\title{
Intraoperative and postoperative corneal thickness change after collagen crosslinking therapy
}

\author{
Ziad Hassan', Laszlo Modis Jr. ${ }^{2}$, Eszter Szalai², Andras Berta², Gabor Nemeth² \\ ${ }^{1}$ Orbident Refractive Surgery and Medical Center \\ ${ }^{2}$ Department of Ophthalmology, Medical and Health Science Center, University of Debrecen - Hungary
}

\begin{abstract}
Purpose: To assess intraoperative and postoperative changes in corneal thickness subsequent to riboflavin-UVA (collagen crosslinking [CXL]) treatment.

Methods: Forty-one eyes of 41 patients (mean age $27.97 \pm 6.97$ years) were treated with CXL technique. During treatment, isotonic riboflavin was instilled and corneal thickness measurements were obtained at the cornea apex, the thinnest point, and the pupil center at 15 and 30 minutes, then 3 days, 1 week, and 1, 3, 6, and 12 months after surgery using Pentacam HR and an ultrasound pachymeter.

Results: $A$ decrease in corneal thickness was detected 15 minutes intraoperatively with a value of 108.95 $\pm 48.6 \mu \mathrm{m}$, and $112.35 \pm 47.3 \mu \mathrm{m}$ at 30 minutes $(p<0.001)$. Three days after the operation, no deviation was found from the initial values $(p=0.17)$. No further changes were detected during the follow-up period. Conclusions: Isotonic riboflavin solution used during CXL treatment resulted in a significant decrease in corneal thickness, but its effect had disappeared by postoperative day 3.
\end{abstract}

Keywords: Collagen crosslinking, Corneal thickness, Isotonic riboflavin, Pentacam HR

Accepted: August 16, 2013

\section{INTRODUCTION}

Collagen crosslinking (CXL) is a promising treatment applied to delay and stop the progression of keratoconus (1-4). On one hand, riboflavin used during treatment acts as a photosensitizer; on the other hand, it protects the corneal endothelium from UVA radiation $(5,6)$. During and subsequent to this treatment, a significant change in corneal thickness can be detected (7-10), thus the protective effect of riboflavin is likely to fail in some cases. Our goal was to assess the changes in the thickness of corneas treated with isotonic riboflavin during and 1 year after surgery.

\section{PATIENTS AND METHODS}

Inclusion criteria for CXL were the following: keratoconus diagnosed on the basis of the known criteria and the
Collaborative Longitudinal Evaluation of Keratoconus Study $(11,12)$; age 18 to 45 years; cornea thicker than $400 \mu \mathrm{m}$ at the thinnest point; and significant decline in visual acuity and/or keratometric values and corneal pachymetry in the past 3-6 months. Further inclusion criteria were optically clear cornea and a lack of Vogt striae or anterior stromal scarring. Exclusion criteria were dry eye syndrome distorting the images captured by Pentacam HR and eye pathology other than keratoconus.

Prior to operation, the following data were recorded: age, sex, and corneal thickness measured at the apex, the pupil center, and the thinnest point of the cornea using Pentacam HR (Pentacam HR, Oculus Optikgeräte $\mathrm{GmbH}$, Wetzlar, Germany, software version 1.17r139). Pentacam $\mathrm{HR}$ is the high-resolution version of the former Pentacam. Using a monochromatic light source $(475 \mathrm{~nm})$ and rotating around the optical axis, the camera captures 25 Scheimpflug images in 2 seconds while also correcting for small eye 
movements. For each examination, 3 of these complete images were captured of every eye and only automatically captured images with no distortion (such as blinking) were included. Additionally, ultrasound measurements were carried out at the center of the cornea at each visit, using an ultrasound pachymeter (PachPen; Accutome Inc., Malvern, Pennsylvania, USA).

\section{Surgical technique}

Topical anesthesia was performed by administering tetracaine hydrochloride eyedrops 15 minutes before the operation and every 5 minutes until the end of the operation. The patient was placed under the operating microscope and a lid speculum was inserted, the epithelium was marked in the inferior paracentral area to be treated (diameter 8-9 $\mathrm{mm}$ ), and the epithelium was removed with a blunt spatula. Before starting UVA irradiation, the cornea was instilled with riboflavin $0.1 \%$, dextran $50020 \%$ solution for 15 minutes (single-use isotonic eyedrops; Medio Cross Medizin Produkte $\mathrm{GmbH}$, Rostock, Germany) with a frequency of every 5 minutes for the drops. In cases of corneas with a central corneal thickness (CCT) of under $400 \mu \mathrm{m}$, we used hypotonic riboflavin solution (single-use hypotonic eyedrops; Medio Cross Medizin Produkte $\mathrm{GmbH}$ ) for 1 hour before irradiation to swell the cornea. Then the cornea was exposed to a UVA 370-nm light (In-Pro CCL-Lix UV, Norderstadt, Germany) for 30 minutes at an irradiance of $3.0 \mathrm{~mW} / \mathrm{cm}^{2}\left(5.4 \mathrm{~J} / \mathrm{cm}^{2}\right)$. During UVA exposure, isotonic riboflavin drops were continued every 2 minutes or more often if the corneal surface appeared visibly dry.

After the first 15-minute treatment, the cornea was rinsed with saline to prevent riboflavin altering measurement values and topical anesthetics were used as most patients complain of eye sensitivity at this stage. The demonstrating 15-minute Pentacam HR images were captured at this stage. In one case, intraoperative images were captured also with a Visante optical coherence tomograph (Visante OCT, Carl Zeiss Meditec, Jena, Germany). Then riboflavin UVA treatment was continued for a further 15 minutes with instillation every 2 minutes. After treatment, the eye surface was washed with antibiotic drops, a process that was followed by the placement of a bandage soft contact lens (Air Optix Night and Day, Alcon, Fort Worth, Texas, USA). Postoperatively, antibiot- ic (3 $\mathrm{mg} / \mathrm{mL}$ tobramycin) drops $5 /$ day were administered for 5 days, corticosteroid ( $1 \mathrm{mg} / \mathrm{mL}$ flurometholone) drops 5/day for a minimum of 1 month starting at postoperative day 5 . The bandage contact lens was removed on postoperative day 3 , at which point slit-lamp examination was performed to confirm the presence of complete corneal re-epithelization. Routine examinations were performed 3 days, 1 week, 1 month, 3 months, 6 months, and 12 months postoperatively.

All treatments were carried out by the same experienced operator. All patients were informed about the details of the examinations and the operation and signed an informed consent. All examinations were conducted according to the protocol of the Declaration of Helsinki.

Statistical analysis was performed with MedCalc 10.0. Descriptive statistical results were described as mean, standard deviation (SD), and 95\% confidence interval $(95 \% \mathrm{Cl})$ for the mean. A Wilcoxon test was carried out for comparisons between groups or variables, and a Spearman rank test for correlation. A $p$ value below 0.05 was considered statistically significant.

\section{RESULTS}

Forty-one eyes of 41 patients were treated with CXL technique. The mean age was $27.97 \pm 6.97$ years $(95 \%$ Cl 25.77-30.17, range 18-44.06 years).

Compared to the preoperative data, corneal thickness was significantly thinner at 15 minutes and 30 minutes during treatment $(p<0.001)$ using Pentacam HR. The average decrease was $108.95 \pm 48.6 \mu \mathrm{m}$ at 15 minutes and $112.35 \pm 47.3 \mu \mathrm{m}$ at 30 minutes intraoperatively using Pentacam HR. The rate of the decrease showed no correlation with the initial corneal thickness values $(r=0.16 ; p=0.7)$. Three days after the operation, no statistically significant deviation was found between the measured points and the initial values using Pentacam $(p=0.17)$ and ultrasound device $(p=0.32)$. No further changes were detected during the follow-up period. Our corneal pachymetry data are summarized in Tables I and II and illustrated in Figure 1. Intraoperative images were captured by Pentacam HR and Visante OCT (Fig. 2). A hyper-reflective corneal tissue zone can be clearly seen in Pentacam HR images but is not distinctly visible in Visante OCT. 
TABLE I - CORNEAL THICKNESS MEASUREMENTS IN $\mu$ M AT THE CORNEAL APEX, THE THINNEST CORNEAL POINT (MIN), AND PUPIL CENTER (PUPIL) PRIOR TO COLLAGEN CROSSLINKING, INTRAOPERATIVELY, AND IN THE POSTOPERATIVE FOLLOW-UP PERIOD, USING PENTACAM HR

\begin{tabular}{|c|c|c|c|c|c|}
\hline & Mean & SD & $95 \% \mathrm{Cl}$ & Minimum & Maximum \\
\hline \multicolumn{6}{|c|}{ Preoperative } \\
\hline Min & 446.74 & 51.692 & $430.209-463.273$ & 298 & 559.67 \\
\hline Pupil & 472.83 & 49.577 & $456.978-488.689$ & 321.33 & 569.33 \\
\hline Min & 341.99 & 65.61 & $321.009-362.975$ & 165.67 & 459 \\
\hline Pupil & 359.13 & 64.101 & $338.633-379.634$ & 192 & 481.67 \\
\hline \multicolumn{6}{|c|}{30 minutes } \\
\hline Apex & 351.25 & 53.277 & $334.212-368.289$ & 233.67 & 458 \\
\hline Apex & 484.53 & 78.136 & $459.201-509.859$ & 275.67 & 666.33 \\
\hline Min & 466.56 & 81.392 & $440.171-492.940$ & 222.67 & 646.33 \\
\hline Pupil & 490.33 & 76.608 & $465.500-515.167$ & 295.33 & 667.67 \\
\hline \multicolumn{6}{|l|}{1 week } \\
\hline Apex & 467.45 & 62.92 & $447.057-487.849$ & 298.33 & 592 \\
\hline Min & 450.72 & 60.394 & 431.141-470.296 & 290.67 & 561 \\
\hline Pupil & 476.83 & 59.366 & $457.585-496.073$ & 322 & 593.67 \\
\hline \multicolumn{6}{|l|}{1 month } \\
\hline Pupil & 467.24 & 49.303 & $449.464-485.015$ & 327.67 & 573.33 \\
\hline \multicolumn{6}{|c|}{6 months } \\
\hline Apex & 444.29 & 53.633 & $422.154-466.432$ & 296.33 & 526.33 \\
\hline Min & 429.39 & 51.364 & $408.186-450.589$ & 293 & 506 \\
\hline Pupil & 457.76 & 47.916 & $437.983-477.540$ & 329.67 & 532.67 \\
\hline \multicolumn{6}{|c|}{12 months } \\
\hline Apex & 441.02 & 55.775 & $412.343-469.696$ & 294 & 523 \\
\hline Min & 426.35 & 52.725 & $399.244-453.462$ & 289.67 & 502.67 \\
\hline Pupil & 454.59 & 49.264 & $429.258-479.917$ & 329.33 & 531 \\
\hline
\end{tabular}

$\mathrm{Cl}=$ confidence interval; $\mathrm{SD}=$ standard deviation. 
[Author: Please provide high res images fig. 1 \& 2.]

TABLE II - CORNEAL THICKNESS MEASUREMENTS IN $\mu \mathrm{M}$ AT THE CENTER OF THE CORNEA PRIOR TO COLLAGEN CROSSLINKING, INTRAOPERATIVELY, AND IN THE POSTOPERATIVE FOLLOW-UP PERIOD, USING AN ULTRASOUND PACHYMETER

\begin{tabular}{lccccc}
\hline & Mean & SD & $95 \%$ CI & $\begin{array}{c}\text { Mini- } \\
\text { mum }\end{array}$ & $\begin{array}{c}\text { Maxi- } \\
\text { mum }\end{array}$ \\
\hline Preoperative & 475.80 & 58.763 & $457.007-494.593$ & 317 & 590 \\
15 minutes & 339.88 & 57.529 & $321.476-358.274$ & 205 & 460 \\
30 minutes & 330.03 & 44.748 & $315.714-344.336$ & 207 & 460 \\
3 days & 474.71 & 69.928 & $450.693-498.735$ & 311 & 580 \\
1 week & 475.80 & 56.937 & $457.591-494.009$ & 310 & 565 \\
1 month & 470.49 & 56.764 & $451.560-489.413$ & 310 & 567 \\
3 months & 468.74 & 54.216 & $447.294-490.188$ & 320 & 557 \\
6 months & 463.36 & 48.423 & $443.372-483.348$ & 325 & 555 \\
12 months & 460.12 & 54.690 & $431.999-488.237$ & 325 & 554 \\
\hline
\end{tabular}

$\mathrm{Cl}=$ confidence interval; $\mathrm{SD}=$ standard deviation .

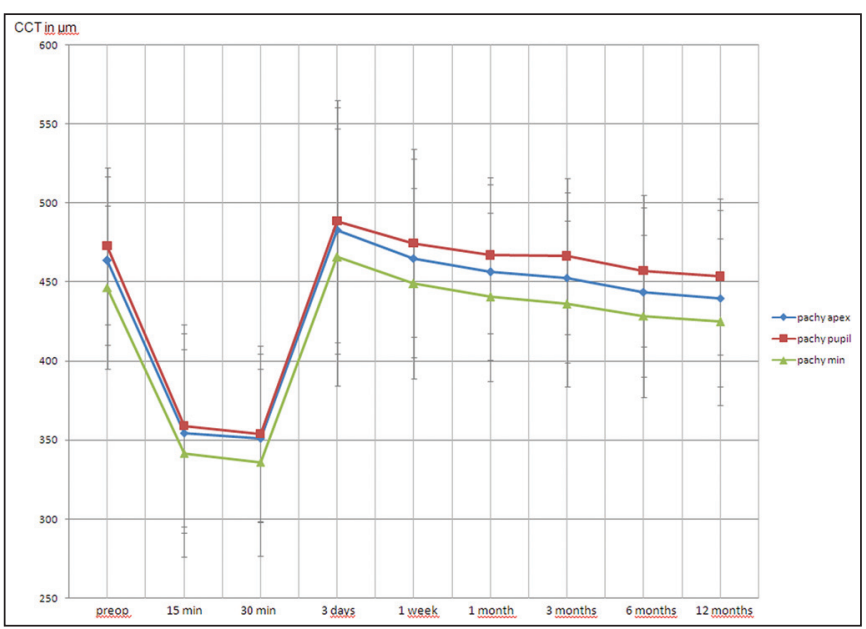

Fig. 1 - Mean corneal thickness changes at 15 minutes and 30 minutes during collagen crosslinking and 3 days, 1 week, 1,3 , 6 , and 12 months after treatment. In every case, thickness measurements at the corneal apex (apex), pupil center (pupil), and the thinnest point of the cornea (min) were recorded. CCT = central corneal thickness.

\section{DISCUSSION}

The purpose of CXL treatment is to establish new chemical bonds in corneal stroma induced by riboflavin and 370-nm UVA light. On one hand, riboflavin acts as a photosensi-

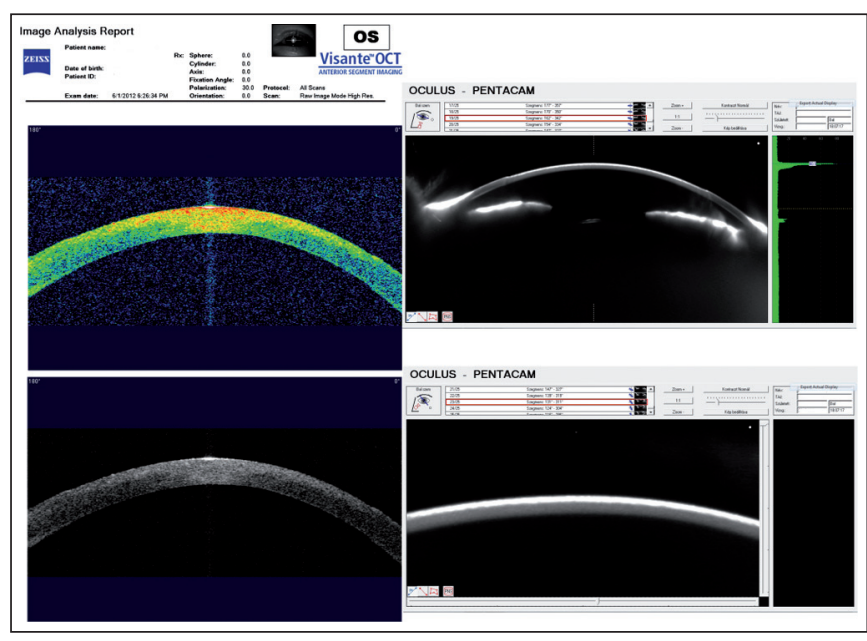

Fig. 2 - Pentacam HR and Visante optical coherence tomography (OCT) images captured at 15 minutes during collagen crosslinking treatment. Hyperreflective corneal tissue zone can be seen in Pentacam HR pictures (right) and not distinctly visible in Visante OCT pictures (left).

tizer during treatment; on the other hand, it protects the areas below the treatment zone from the effects of the UVA radiation $(5,6)$. The aim of the treatment is to increase the rigidity and the biomechanical strength of the cornea. This therapy has been widely used for the treatment of progressive keratoconus (1-4), although its other diagnostic abilities are also well-known (13). Both objective $(14,15)$ and subjective (16) improvements were reported in eyes with keratoconus after CXL treatment, even in subjects under 18 (17).

As collagen bonds are established at a depth of 250$350 \mu \mathrm{m}$ in the anterior stroma, called the treatment zone $(5,18-21)$, and for the protection of the endothelium, a minimum of $400 \mu \mathrm{m}$ stromal thickness is suggested $(5,22)$. However, according to other publications, a minimum of $330 \mu \mathrm{m}$ of initial thickness is also sufficient for CXL after corneal swelling (23). Transepithelial CXL or customized pachymetric guided epithelial debridement may be beneficial in cases where corneal thickness is thinner than $400 \mu \mathrm{m}(24,25)$. Our study comprised 2 patients who had refused any surgical procedure, where the initial corneal thickness value was under $300 \mu \mathrm{m}$. According to our experience, it is safe to use isotonic riboflavin after corneal swelling is achieved with hypotonic riboflavin solution. However, in our practice a preoperative treatment limit of at least $400 \mu \mathrm{m}$ is used.

Our study aimed to reveal the process of how the wellknown changes in corneal thickness after CXL therapy 
$(7,10,26,27)$ occur at a less investigated intraoperative stage and in the follow-up period.

Administering isotonic riboflavin, Greenstein et al (28) measured pupil, apical, and the thinnest corneal thickness as being 23-24.6 $\mu \mathrm{m}$ thinner 1 month after treatment using Scheimpflug analysis. At 1 year, apex and pupil center thicknesses returned to the baseline; however, the thinnest pachymetry remained slightly lower than baseline and similar values were found for pupil, apex, and thinnest pachymetry thicknesses (28). The gradually increasing values did not reach preoperative readings until 1 year after the operation. Data were compared with ultrasound pachymetry, but were analyzed only preoperatively (28). A number of other studies reported changes in corneal thickness after CXL treatment and, in every case, a decrease was observed $(7-10,26,27)$. Despite the findings mentioned above, corneal thickening was reported 3 days after CXL in rabbit cornea, which ceased only 1 week later (29). So it seems that corneal tissues may react differently to the treatment due to structural differences.

It has also been suggested that changes in corneal thickness observed using Scheimpflug analysis can be an artefact $(30,31)$ resulting from postoperative corneal haze $(8,9,32)$. In our study, ultrasonic measurements were also carried out subsequent to treatments, which showed similar results preoperatively and from 1 week after CXL. However, intraoperatively and at the 3-day visit, ultrasound pachymetry measured smaller CCT than Pentacam. The possibly altered refractive index of crosslinked corneas can be the background of this difference.

Results obtained with Scheimpflug analysis and ultrasound measurements correlate well with each other. The thinning of the cornea and stromal haze can be explained by structural and physiologic wound-healing changes developing after treatment (33), though the mechanism of corneal re-thickening remains unexplained.

A limitation of our study is that subsequent to de-epithelization no Pentacam HR images were captured. Normal epithelial thickness was reported as $53.4 \pm 4.6 \mu \mathrm{m}$ (34), a value supported by the data reported by Kymionis et al of $43 \mu \mathrm{m}$ (35). When this mean epithelial thickness is subtracted from the thickness that we measured preoperatively, the decrease in the corneal thickness remains highly significant $(p<0.01)$.

During pachymetric measurements, corneal thickness was analyzed at the thinnest point and in the pupil center. The readings of Henriquez et al (36) showed a mean corneal thinning from $56 \mu \mathrm{m}$ to $13 \mu \mathrm{m}$ at the thinnest point of the cornea 1 and 12 months after treatment. Vinciguerra et al (14) found a significantly thinner cornea in the pupil center even 1 year after treatment; however, they showed no significant change vs the thinnest pachymetry location in eyes with keratoconus 1 year after the CXL operation. Both authors performed central CXL operation. In our study, the corneal thickness returned to the preoperative level on postoperative day 3 , which remained stable in each of the 3 measured points even at the end of the 1-year follow-up.

Publications suggest corneal thinning in the early postoperative stage, so UVA light can reach corneal endothelium intraoperatively. Therefore, hypoosmolar riboflavin solution is suggested in order to achieve corneal iatrogenic swelling (37), although according to previous research it has only a short-term effect and does not even last until the end of the treatment (38).

Publications found in the literature clearly describe the CCT decrease observed after CXL treatment, though only a few and contradicting reports were carried out on the characteristics of CCT decrease in the intraoperative phase $(35,38,39)$. Using isotonic solution, Kymionis et al (35) detected a mean $75 \mu \mathrm{m}$ CCT decrease between epithelial removal and riboflavin instillation with ultrasound pachymetry measurements; however, they found no further changes in corneal thickness during irradiation. These data correlate well with our data regarding the decrease in thickness. Kaya et al (38) measured corneal thickness at 5 different times: the thinnest pachymetry data decreased to a mean of $376 \mu \mathrm{m}$ after the epithelial removal and by a mean of $55 \mu \mathrm{m}$ after the 30-minute application of the isotonic riboflavin solution. The 10-minute application of hypotonic riboflavin resulted in the cornea thickening by a mean of $59 \mu \mathrm{m}$. Ten and 30 minutes after the instillation of isotonic riboflavin solution, the thinnest pachymetric readings showed a decrease with a value of 50 and $65 \mu \mathrm{m}$. Holopainen and Krootila (39) measured corneal thickness both preoperatively and postoperatively using ultrasound pachymeter and found a thinning of a mean $87 \mu \mathrm{m}$ during the 1-hour operation. Depending on the initial corneal thickness, they administered isotonic or hypotonic solution. Compared to the preoperative CCT, they reported a significantly lower value 1 month after the operation and found the same value 6 months after treatment. In our study, corneal thickness reached the initial value 3 days after treatment. 
In summary, a significant decrease in corneal thickness can be observed during CXL treatment applied for treating keratoconus. However, this change is temporary and the value measured initially is reached 3 days after treatment. Further investigations are suggested in order to determine whether this change may have any consequences or whether it is of any significance.

Financial Support: No financial support was received for this submission.
Conflict of Interest Statement: None of the authors has conflict of interest with this submission.

Address for correspondence:

Gabor Nemeth, MD, PhD

Department of Ophthalmology

University of Debrecen

Nagyerdei Blvd. 98

H-4012 Debrecen

Hungary

nemeth222@yahoo.com

\section{REFERENCES}

1. Seiler T, Hafezi F. Corneal cross-linking-induced stromal demarcation line. Cornea 2006;25:1057-9.

2. Spoerl E, Huhle M, Seiler T. Induction of cross-links in corneal tissue. Exp Eye Res 1998;66:97-103.

3. Kohlhaas M, Spoerl E, Schilde T, Unger G, Wittig C, Pillunat LE. Biomechanical evidence of the distribution of crosslinks in corneas treated with riboflavin and ultraviolet A light. J Cataract Refract Surg 2006;32:279-83.

4. Wollensak G, Spoerl E, Seiler T. Stress-strain measurements of human and porcine corneas after riboflavinultraviolet-A-induced cross-linking. J Cataract Refract Surg 2003;29:1780-5.

5. Spoerl E, Mrochen M, Sliney D, Trokel S, Seiler T. Safety of UVA-riboflavin cross-linking of the cornea. Cornea 2007;26:385-9.

6. Wollensak G, Spörl E, Reber F, Pillunat L, Funk R. Corneal endothelial cytotoxicity of riboflavin/UVA treatment in vitro. Ophthalmic Res 2003;35:324-8.

7. Caporossi A, Baiocchi S, Mazzotta C, Traversi C, Caporossi T. Parasurgical therapy for keratoconus by riboflavin-ultraviolet type A rays induced cross-linking of corneal collagen: preliminary refractive results in an Italian study. $\mathrm{J}$ Cataract Refract Surg 2006;32:837-45.

8. Caporossi A, Mazzotta C, Baiocchi S, Caporossi T. Longterm results of riboflavin ultraviolet a corneal collagen crosslinking for keratoconus in Italy: the Siena eye cross study. Am J Ophthalmol 2010;149:585-93.

9. Raiskup-Wolf F, Hoyer A, Spoerl E, Pillunat LE. Collagen crosslinking with riboflavin and ultraviolet-A light in keratoconus: long-term results. J Cataract Refract Surg 2008; 34:796-801.

10. Grewal DS, Brar GS, Jain R, Sood V, Singla M, Grewal SP. Corneal collagen crosslinking using riboflavin and ultravioletA light for keratoconus: one-year analysis using Scheimpflug imaging. J Cataract Refract Surg 2009;35:425-32.

11. Rabinowitz YS. Keratoconus. Surv Ophthalmol 1998;42: 297-319.
12. Barr JT, Wilson BS, Gordon MO, et al. CLEK Study Group. Estimation of the incidence and factors predictive of corneal scarring in the Collaborative Longitudinal Evaluation of Keratoconus (CLEK) Study. Cornea 2006;25:16-25.

13. Cordeiro Barbosa MM, Barbosa JB Jr, Hirai FE, Hofling-Lima AL. Effect of cross-linking on corneal thickness in patients with corneal edema. Cornea 2010;29:613-7.

14. Vinciguerra P, Albè E, Trazza S, et al. Refractive, topographic, tomographic, and aberrometric analysis of keratoconic eyes undergoing corneal cross-linking. Ophthalmology 2009;116:369-78.

15. Greenstein SA, Fry KL, Hersh PS. Corneal topography indices after corneal collagen crosslinking for keratoconus and corneal ectasia: one-year results. J Cataract Refract Surg 2011;37:1282-90.

16. Brooks NO, Greenstein S, Fry K, Hersh PS. Patient subjective visual function after corneal collagen crosslinking for keratoconus and corneal ectasia. J Cataract Refract Surg 2012;38:615-9.

17. Caporossi A, Mazzotta C, Baiocchi S, Caporossi T, Denaro $R$, Balestrazzi A. Riboflavin-UVA-induced corneal collagen cross-linking in pediatric patients. Cornea 2012;31: 227-31.

18. Esquenazi S, He J, Li N, Bazan HE. Immunofluorescence of rabbit corneas after collagen cross-linking treatment with riboflavin and ultraviolet A. Cornea 2010;29:412-7.

19. Wollensak G. Histological changes in human cornea after crosslinking with riboflavin and ultraviolet A. Acta Ophthalmol 2010;88:e17-8.

20. Wollensak G, Spoerl E, Wilsch M, Seiler T. Keratocyte apoptosis after corneal collagen cross-linking using riboflavin/ UVA treatment. Cornea 2004;23:43-9.

21. Mazzotta C, Traversi C, Baiocchi S, Sergio P, Caporossi T, Caporossi A. Conservative treatment of keratoconus by riboflavin-UVA-induced cross-linking of corneal collagen: qualitative investigation. Eur J Ophthalmol 2006;16:530-5.

22. Wollensak G. Crosslinking treatment of progressive keratoconus: new hope. Curr Opin Ophthalmol 2006;17: 356-60 
23. Hafezi F. Limitation of collagen cross-linking with hypoosmolar riboflavin solution: failure in an extremely thin cornea. Cornea 2011;30:917-9.

24. Wollensak G, lomdina E. Biomechanical and histological changes after corneal crosslinking with and without epithelial debridement. J Cataract Refract Surg 2009;35:540-6.

25. Kymionis GD, Diakonis VF, Coskunseven E, Jankov M, Yoo $\mathrm{SH}$, Pallikaris IG. Customized pachymetric guided epithelial debridement for corneal collagen cross linking. BMC Ophthalmol 2009;9:10.

26. Vinciguerra P, Camesasca FI, Albè E, Trazza S. Corneal collagen cross-linking for ectasia after excimer laser refractive surgery: 1-year results. J Refract Surg 2010;26:486-97.

27. Koller T, Iseli HP, Hafezi F, Vinciguerra P, Seiler T. Scheimpflug imaging of corneas after collagen cross-linking. Cornea 2009;28:510-5.

28. Greenstein SA, Shah VP, Fry KL, Hersh PS. Corneal thickness changes after corneal collagen crosslinking for keratoconus and corneal ectasia: one-year results. J Cataract Refract Surg 2011;37:691-700.

29. Hovakimyan M, Guthoff R, Knappe S, et al. Short-term corneal response to cross-linking in rabbit eyes assessed by in vivo confocal laser scanning microscopy and histology. Cornea 2011;30:196-203.

30. de Sanctis U, Missolungi A, Mutani B, Richiardi L, Grignolo FM. Reproducibility and repeatability of central corneal thickness measurement in keratoconus using the rotating Scheimpflug camera and ultrasound pachymetry. Am J Ophthalmol 2007;144:712-8.

31. Grewal DS, Brar GS, Grewal SPS. Assessment of central corneal thickness in normal, keratoconus, and post-laser in situ keratomileusis eyes using Scheimpflug imaging, spec- tral domain optical coherence tomography, and ultrasound pachymetry. J Cataract Refract Surg 2010;36:954-64.

32. Mazzotta C, Traversi C, Baiocchi S, et al. Corneal healing after riboflavin ultraviolet-A collagen cross-linking determined by confocal laser scanning microscopy in vivo: early and late modifications. Am J Ophthalmol 2008;146:527-33.

33. Corbett MC, Prydal JI, Verma S, Oliver KM, Pande M, Marshall J. An in vivo investigation of the structures responsible for corneal haze after photorefractive keratectomy and their effect on visual function. Ophthalmology 1996;103:1366-80.

34. Reinstein DZ, Archer TJ, Gobbe M, Silverman RH, Coleman DJ. Epithelial thickness in the normal cornea: three-dimensional display with Artemis very high-frequency digital ultrasound. J Refract Surg 2008;24:571-81.

35. Kymionis GD, Kounis GA, Portaliou DM, et al. Intraoperative pachymetric measurements during corneal collagen crosslinking with riboflavin and ultraviolet $A$ irradiation. Ophthalmology 2009;116:2336-9.

36. Henriquez MA, Izquierdo L Jr, Bernilla C, Zakrzewski PA, Mannis M. Riboflavin/Ultraviolet A corneal collagen crosslinking for the treatment of keratoconus: visual outcomes and Scheimpflug analysis. Cornea 2011;30:281-6.

37. Hafezi F, Mrochen M, Iseli HP, Seiler T. Collagen crosslinking with ultraviolet-A and hypoosmolar riboflavin solution in thin corneas. J Cataract Refract Surg 2009;35:621-4.

38. Kaya V, Utine CA, Yılmaz ÖF. Intraoperative corneal thickness measurements during corneal collagen cross-linking with hypoosmolar riboflavin solution in thin corneas. Cornea 2012;31:486-90.

39. Holopainen JM, Krootila K. Transient corneal thinning in eyes undergoing corneal cross-linking. Am J Ophthalmol 2011;152:533-6. 